\title{
An I-Based Taxonomy of Virtual Organisations and the Implications for Effective Management
}

\author{
Nick Lethbridge \\ School of Management Information Systems, \\ Edith Cowan University, Australia
}

\author{
níckleth@,multitine.com.au
}

\begin{abstract}
This paper expands on the taxonomy of virtual organisation (VO) structures based on the cross-boundary information flow requirements of member organisations within the VO. Each structure is described, with the essential implications for effective management. That is, what particular features of the VO must management take account of if that VO structure is to be implemented. Management implications to be considered are: Existence of a core organisation, Member organisation replaceability, Planning, Customer contact, Information flows, Suitability of management for each member organisation. The structures are further explained by use of two extended examples. Three information flows are used to define the taxonomy: Planning, Operational and Coordination information. The structures of the i-based VO taxonomy are: Virtual face, Star alliance, Market alliance, Coalliance, Value alliance, Parallel alliance.
\end{abstract}

Keywords: virtual organisation, VO, i-based, taxonomy, management

\section{Introduction}

The ability to form a good business partnership, to successfully collaborate, has been described as a key corporate asset (Kanter, 1994). Kanter identifies eight key factors for a successful intercompany collaborative relationship. Of those eight, "information" is central to the theme of this paper.

A good business partnership is an essential ingredient for a successful organisation. This paper supports partnering with a clear taxonomy of structures for collaboration. Each structure is simpler than most that exist "in real life". The lessons to be learned, however, the implications for successful management of a collaboration, are extremely practical.

The exchange of business information is an essential part of a business partnership. The electronic exchange of information through an IT network, between separate organisations or between an organisation and its customers, is a part of e-business. B2B (business-to-business) e-business may be used to support successful business partnerships.

Material published as part of this journal, either on-line or in print, is copyrighted by the publisher of Informing Science. Permission to make digital or paper copy of part or all of these works for personal or classroom use is granted without fee provided that the copies are not made or distributed for profit or commercial advantage AND that copies 1) bear this notice in full and 2) give the full citation on the first page. It is permissible to abstract these works so long as credit is given. To copy in all other cases or to republish or to post on a server or to redistribute to lists requires specific permission and payment of a fee. Contact Editor@inform.nu to request redistribution permission.
B2B e-business is one aspect of the recently defined "virtual organisation", or VO. A "virtual" organisation is formed by agreement of separate organisations to collaborate, to share knowledge and expertise, in order to achieve a common purpose. A virtual organisation is a group of companies, or a group of legally separate entities, that act as though they were one.

A virtual organisation consists of "member" organisations. The customer deals with what appears to be one organisation. To ensure that the customer sees only one "virtual" organisation, the member organisations coordinate their activities. The member organisations form a business partnership. They collaborate.

Communication, the exchange of information, is important to an alliance, to a $\mathrm{VO}$ (virtual organisation). Understanding of the essential information flows between members will increase the likelihood of overall success for the virtual organisation. This paper builds on the information based (i-based) taxonomy of the virtual organisation (Lethbridge, 2000). The VO structures are now used to gain insight into the requirements for effective management of a virtual organisation.

This remainder of this paper is presented in several parts:

- A broad outline of the management implications that are affected by choice of a virtual organisation structure within the i-based taxonomy. 
- The taxonomy is described with, for each structure, specific management implications and examples based on a possible "virtual university" and a car manufacturer.

- Summary and conclusions.

\section{Management Implications for a VO}

A virtual organisation, like any other organisation, must be managed. The fact that it is "virtual", that it is a group of independent organisations acting to achieve a common purpose, has implications for VO management. These implications are listed below then briefly described. They are then applied, where relevant, in the descriptions of the VO models.

- A core organisation may exist

- VO members may be replaceable

- Planning (when and where is it done)

- Customer contact

- Categories of information flows

- Management must suit each member

There may be a "core" organisation, one with a particular management role within the VO. The core organisation may drive the VO purpose or it may perform an essential part of the purpose. If a core organisation exists it may be difficult to replace (see next paragraph).

VO member organisations may be replaceable. They may be replaceable in the sense that there may be more or less members with no effect on the overall purpose of the VO. Or they may be replaceable in that a different organisation may be brought into the VO to replace the specific function of a member that is to be removed.

Strategic planning for the VO is essential. Planning will involve different members of the $\mathrm{VO}$ depending on the $\mathrm{VO}$ structure within the i-based taxonomy. The timing of planning (before or during normal operation) will also be affected.

The customer should see only one "virtual" organisation. How well this works will depend on the VO structure. Depending on the structure there may be only one, several or all members in regular contact with the customers of the VO.

Three categories of information flow are used to define the i-based taxonomy. Identification of the VO structure leads to understanding of necessary information flows. This in turn leads to a better understanding of the strengths and weaknesses of each possible structure.

VO management must suit each VO member. One member may have (or may take) extra power within the VO. This may allow it to dictate some management decisions to other members. Nevertheless, each member is an independent organisation, with its own internal management rules, regulations and management requirements. Each member must operate as both a member of a $\mathrm{VO}$ and as an independent organisation.

There are three further points that apply to all VOs, regardless of structure. They are always relevant but are not discussed separately for each structure.

First, a VO may be a complex structure. The i-based taxonomy describes simple, elemental structures. A practical VO will be a combination of these elemental structures. Second, each member of a VO may also be a member of one or more other VOs. Individuals, groups or the entire member organisation may simultaneously operate within several VOs. This has an impact on restrictions that may be imposed by VO management. It imposes limits on the adaptability of any member organisation within each VO.

Third, the principles of VO management may also be applied within a single company. A VO comprises several independent organisations. A company may comprise several departments, each with a degree of operational independence. The same principles that allow independent organisations to work together may equally be applied within a "virtual enterprise" (VE) (Sandhoff, 1999). Within the VE, departments are able to maintain some autonomy. The departments exchange sufficient information to ensure that the common purpose of the organisation (of the VE) is achieved.

\section{The i-Based Taxonomy}

\section{Earlier work on the taxonomy}

The i-based taxonomy is a rationalisation and extension of models developed over a series of papers by various authors. For more detail on these models see, for example, (Burn \& Tetteh, 2000; Burn \& Barnett, 1999; Burn, Marshall, \& Wild, 1999; Marshall, McKay, \& Burn, 2001).

Earlier versions of this taxonomy showed linkages between members of a VO, but did not give details of the form of the linkages. That is, the models had no inter-organisational information flows. The author of this paper added information flows to the taxonomy.

The first version of the i-based taxonomy was presented at a conference (Lethbridge, 2000). This paper presents a refined model with business-based examples. This paper also describes the implications for management of each of the VO models within the i-based taxonomy.

\section{Essential information flows}

The i-based taxonomy defines necessary information flows between member organisations. Three broad categories of information flow are used: 
- Planning: Information used for defining the shared purpose, for setting the scope and direction for overall VO operations.

- Operational: Information used in the day-to-day activities of each member organisation.

- Coordination: Information flows to ensure that operational activities effectively support the shared purpose of the VO.

These information flows are based on the business tasks that each flow supports. Literature provides alternate views of essential tasks and information flows. See, for example, Klueber's "business services" (Klueber, Alt, \& Osterle, 1999), Ahuja's categories from a case study (Ahuja \& Carley, 1988) and various combinations of the traditional management tasks of plan, organise, direct and control (Bush \& Robbins, 1991; Ginnodo, 1992; Kibler, 1992; Yates \& Rahbar, 1992).

\section{Previous views of the virtual organisation}

The literature provides a wide range of models for virtual organisations. Much has been duplicated, sometimes using different terms for the same dimensions. The author found no earlier taxonomy that used information flows as a part of the structure definitions.

Other authors have categorised VOs by other methods.

Bultje adapted other sources to develop a VO typology (Bultje \& van Wijk, 1998). Angehrn developed the "ICDT" model (Information, Communication, Distribution, Transaction) (Angehrn, 1997). Hoffman describes the Web as an efficient and active channel for marketing communications (Hoffman, Novak, \& Chaterjee, 1995), but with no advice on the organisational structures behind the various forms of Web presence.

Sarkar lists a number of intermediary functions and a larger number of new cybermediary functions (Sarkar, Butler, \& Steinfield, 1995), but with few insights into VO structure. Sieber looks at the "motives" for the formation of a virtual organisation (Sieber, 1998). Timmers identifies eleven Webbased business models for the VO (Timmers, 1998).

Finally Sandhoff offers the "virtual organisation" and the "virtual enterprise" (Sandhoff, 1999). This highlights the fact that a virtual organisation may, in fact, have much in common with the structure and operation of a non-virtual organisation of a similar size and complexity.

These virtual business models provide an understanding of the shared purpose, but little information on relevant management structures. And there is no consideration of the requirements for information flows between VO members.

\section{The i-based VO taxonomy}

The i-based taxonomy defines basic, elemental structures for a virtual organisation. These are briefly listed and then described in more detail, with examples, below.

- Virtual Face: A cyberspace incarnation of a non-virtual organisation.

- Star Alliance: A grouping of independent organisations, with a core organisation taking the lead management role.

- Market Alliance: A core organisation manages all sales contacts for the other member organisations.

- Co-alliance: A grouping of independent organisations, each with equal commitment to the alliance.

- Value Alliance: Each member organisation adds value to the work of the previous organisation in the value (or supply) chain.

- Parallel Alliance: One member organisation adds value to the work that is being done concurrently by another virtual organisation member.

\section{Virtual Face}

Virtual Face (Figure 1): A cyberspace incarnation of an existing non-virtual organisation. The Internet (for example) is used to provide services equivalent to or in addition to those available in a physical shop or office. The Virtual Face may reflect all or part of the physical organisation.

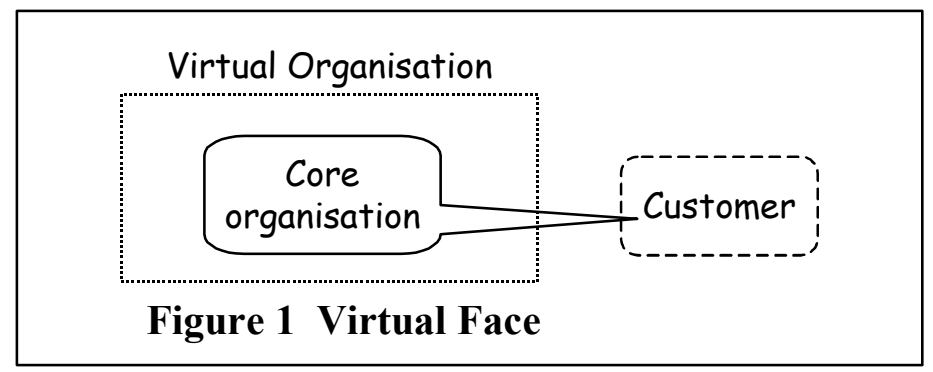

This is the simplest virtual organisation structure. It represents basic B2C (business-to-customer) e-commerce or e-business. The typical virtual face organisation is offering an electronic shop front to its customers. Even this simple structure has its implications for management:

- The e-business group may be split from the "physical" business group. In this case, a new VO structure has been selected.

- The core (and only) VO member is irreplaceable. It is wholly responsible for VO planning, operation, coordination and customer contact.

- With only one member there are no information flows "between members". There is an exchange of operational information with the customer (orders and delivery notes, for example). This is not a part of the $\mathrm{VO}$ taxonomy. 
Management Implications of an I-Based VO Taxonomy

Example: If a university were to offer its courses online, through the Internet, it could use a Virtual Face VO structure, with students as the customers. All student interaction (from enrolment, to lectures, tutorials, assignments and results) would be on-line. The student would have no need to visit a physical university campus.

Example: A car manufacturer could manage orders from its dealers through an Internet sales office. Dealers (customers of the manufacturer) would access the Internet site, select required vehicles and place orders. The Internet would provide a Virtual Face, an electronic replacement for physical contact via phone, post or personal visit.

\section{Star Alliance}

Star Alliance (Figure 2): A grouping of independent organisations, with a core organisation taking the lead role. The core organisation may have key knowledge and other resources, and will present the virtual face of the virtual organisation to customers.

A company that has outsourced some of its operations may operate as a "star alliance". The star alliance structure may also be used for project work, with the core organisation taking responsibility for customer relations and overall project management. It may be created for a single project then dissolved at the end of the project. Or a core organisation may form several star alliances (with varying member organisations) and expect to use the same supporting management structure for each separate alliance.

- The core organisation is essential to the Star Alliance; it may not be replaced. Other "satellite" VO members will normally have been selected to perform a particular function within the VO. Each satellite may be replaced by a new member able to perform the same function.

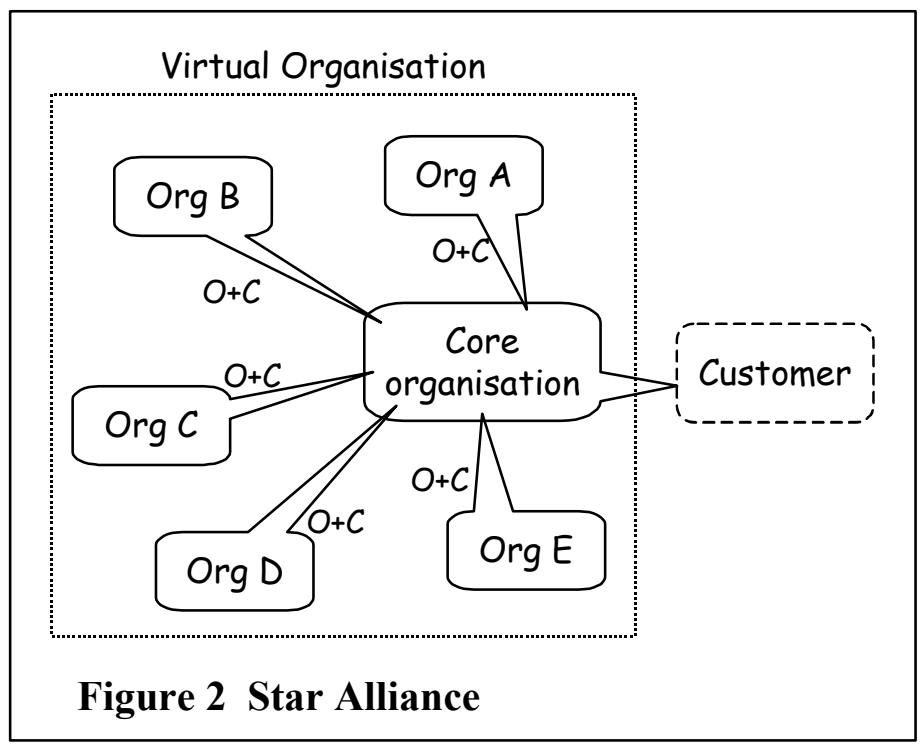

- Planning for the VO is done by the core organisation, as and when required. Satellite members will make their own internal plans, to match the VO plans provided by the core organisation.

- All customer contact is through the core organisation.

- Only Operational and Coordination information flows between members, not Planning. The core organisation instructs the members (operational information) and ensures that the overall VO purpose is being met (coordination).

- Management must suit each member but the core organisation may dictate many of the VO rules.

Example: The virtual university may contract out creation of on-line lectures. It may contract a webmaster to allow these lectures to be set up on an external ISP (internet service provider). The Web site is given the university brand; students deal only through the university-controlled Web site. The university is the core organisation of a Star Alliance. Lecturers, webmaster and ISP are satellite organisation members.

Example: The car manufacturer may buy major assemblies from other companies; manufacture of these assemblies has been contracted out. The car manufacturer is the core organisation of a Star Alliance; suppliers are satellite members. The core organisation sells the completed cars to its customers, the car dealers.

\section{Market Alliance}

Market Alliance (Figure 3): This model has a core organisation that manages all marketing and sales contacts with the customers. Where the core organisation of the Star alliance has overall responsibility for virtual organisation management, the core of the Market Alliance is responsible only for the sales and marketing functions.

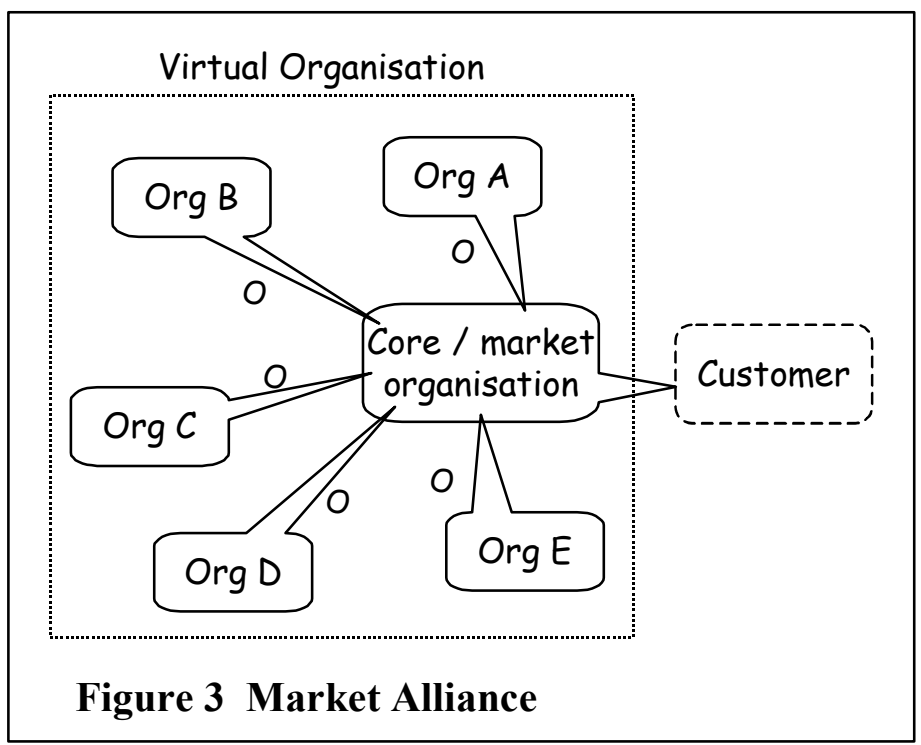


The market may have been created for its own purposes; sellers provide goods for sale and pay a commission for use of the market. Or a group of producers may create its own market, with closed membership, paid for by subscription and commission.

- There is a core organisation but that organisation does not manage the VO. The market will be set up with fixed management rules. A satellite organisation may join the $\mathrm{VO}$ and accept the rules, or it may decide to not join.

- The core organisation is essential to the VO; all other members are replaceable. All satellite members have a similar function, to produce goods or services for sale. There is one core and any number of satellites.

- Planning for the $\mathrm{VO}$ is done before the $\mathrm{VO}$ is created. It may be done by the core organisation, or by the group of satellite organisations that decided to create the shared market organisation. In either case neither planning nor coordination is included in the VO structure.

- The only information flows between members of the Market Alliance are Operational: What goods or services are to be sold, what have been sold. If there are faults in the original plans, there is no correction mechanism in the VO. If, for example, the core organisation changes the way it operates, satellite organisations have no option but to accept the changes or leave.

- All customer contact is with the core organisation, this is the key purpose of the Market Alliance VO.

- VO management must suit each member. If a satellite member is not satisfied it may sell through another market. It may, in fact, already be selling through several VO Market Alliances.

Example: The virtual university may join or create a Market Alliance for its on-line courses. The core organisation may market courses from a number of independent universities. Each university may join a VO for each market segment that it wishes to target. To be a true Market Alliance structure, each course would be "shrink wrapped" and ready to be delivered by the core marketing organisation to the customer.

Example: A car dealer may be seen as the core organisation of a Market Alliance. The dealer may receive cars from several manufacturers, in order to sell the cars to the final consumer. Manufacturers and dealers are independent organisations, bound by the initial planning that led to the market agreement.

\section{Co-alliance}

Co-alliance (Figure 4): A grouping of independent organisations, each with equal commitment to the alliance. The alliance may exist permanently, perhaps with membership changing to match the needs of each project. Each member organisation may deal directly with customers, normally for its own part of the overall project. Membership of the virtual organi-

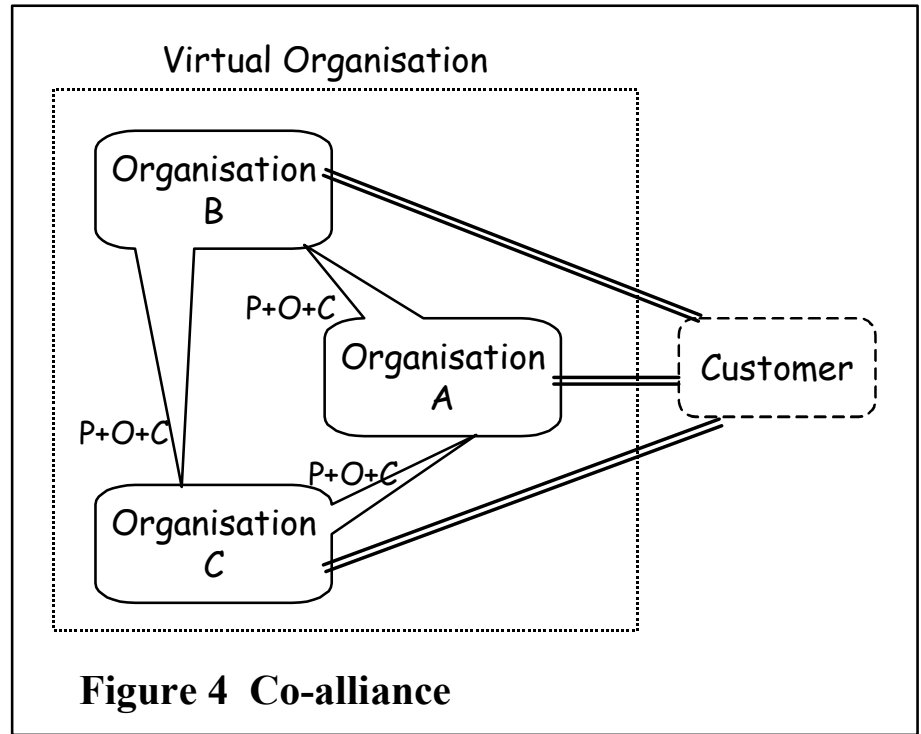

sation will be relatively fixed within the life and scope of each project.

A number of organisations may agree to work together on a project. There may be an agreement to share new work in order to provide a wide range of capabilities to a customer. To maintain its independence, each member of this virtual organisation is an equal partner in $\mathrm{VO}$ management.

- There is no core organisation, no strong leader.

- Each member of the Co-alliance will provide a specific function within the VO. Each member is involved in planning and responsible for coordination. It may be very difficult to replace any member, particularly within the life of a single project.

- All three categories of information flow between all members. With more members, information flow and VO management become more complex.

- Each VO member has a specific function. Each member will contact the customer, to manage that function. If one member organisation takes responsibility for overall management of the project, then a Star Alliance has been formed.

- VO management must suit each member. There is a strong degree of member independence, and members may change between projects.

Example: In the virtual university example, several universities could work with a sales group to penetrate a particular market. The sales group (a member organisation) would sell a course from one university. That university would then present the course to the student. Since all three information flows operate within the VO there is room for the sales organisation to negotiate between student and university. That is, the sales group may facilitate planning and coordination of a course tailored to an individual student. 
Management Implications of an I-Based VO Taxonomy

Example: Three manufacturers, one making cars, one trucks and one motorbikes, may work together to satisfy a major vehicle contract. Each provides unique products (there is no direct competition). The three work as a Co-alliance in order to coordinate deliveries to satisfy customer requirements, and to share transport arrangements to reduce overall costs.

\section{Value Alliance}

Value Alliance (Figure 5): The Value Alliance virtual organisation is based on the value (or supply) chain. Each member organisation adds value to the work of the previous organisation in the chain. The customer places an order with the organisation at the start of the value chain, the product is delivered by the organisation at the end.

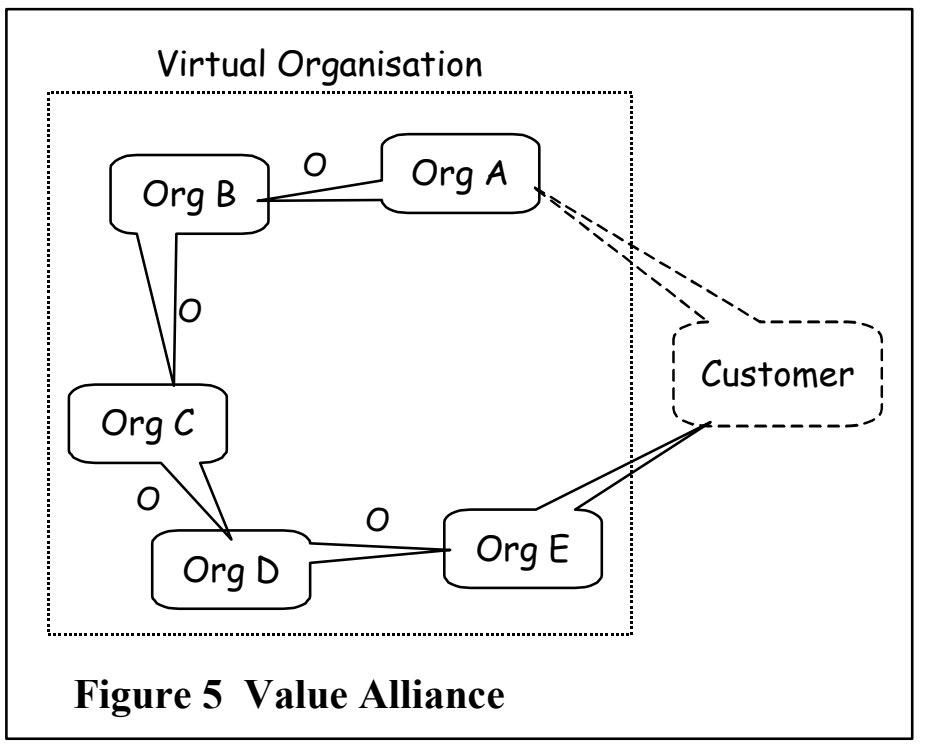

Each member organisation receives a "work in progress" (WIP), a partially complete product or service. The function of the member is to add some value, to move the product closer to completion, then to pass the WIP to the next member on the value chain.

- There is no core organisation.

- VO members may be replaceable, but only by an organisation that is able to add exactly the same value to the total product or service.

- The only information flow is Operational, that is, workin-progress (WIP) being passed to the next organisation in the chain. On receipt of an item of WIP a member organisation will add its value (perform its predefined task) and pass the WIP to the next member in the value chain.

- Once the Value Alliance VO is created there is no built-in planning and coordination, it is assumed that all processes will work. If problems do occur then it can be difficult to correct those problems.

- Customer contact is limited to the first and last organisation in the value chain. This first and last organisation may be the same, a circular value chain. The customer placing an order need not be the same as the customer receiving the finished product. (A customer may order, for example, flowers to be delivered to another person.)

- There is no overall management of the Value Alliance VO. Each member must be able to accept WIP and to pass the value-added WIP to another member.

Example: A virtual university may operate as a Value Alliance. A sales organisation sells a course to a student. Details of the course are passed to the university member of the VO. The university member decides which lecturer is required, then contracts that lecturer. The lecturer, the final "organisation" in the value chain, presents the course to the student.

Example: A car may be manufactured by a Value Alliance VO. One company manufactures steel. A second company shapes the steel into car body parts, a third company assembles the parts into a complete car body. A final organisation within this VO assembles the body, engine and other parts into a complete car. The customer in this example is the ultimate car manufacturer. The decision to produce a certain number of cars results in an order that travels backwards through the value chain, breaking into component parts as it travels.

\section{Parallel Alliance}

Parallel Alliance (Figure 6): The Parallel Alliance reflects a value (or supply) chain where one value-adding organisation must work closely with another. The organisations are responsible for tasks that are mutually dependent. This requires co-

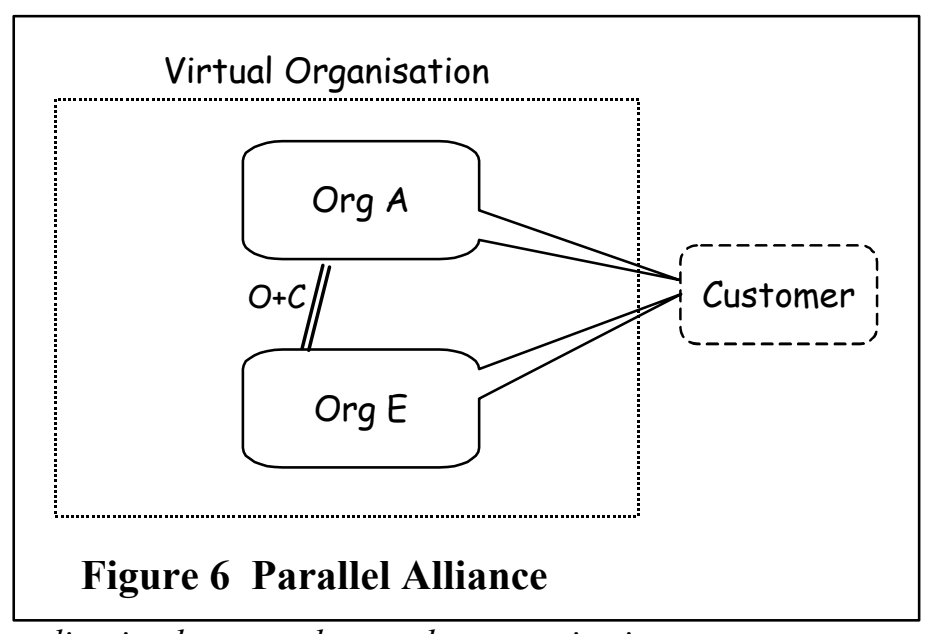

ordination between the member organisations.

This VO structure follows one of Hammer's principles of reengineering: "Link parallel activities instead of integrating their results" (Hammer, 1990). In a virtual organisation the parallel organisations are independent. They cannot be integrated; they must be linked. 
- There is no core organisation.

- VO members may be replaceable, but only by an organisation that is able to add exactly the same value to the total product or service.

- There is both Operational and Coordination information exchanged. This need for coordination makes it more difficult to replace a member in the Parallel Alliance than in the Value Alliance.

- Once the Parallel Alliance VO is created there is no builtin planning. If problems do occur then the Coordination information flows allow corrections to be made, but only within the limits set by the initial planning.

- Customer contact is by both (or all) members of the VO, receiving and providing information relevant to each member's own role in the overall VO purpose.

Example: A virtual university may deliver courses through a Parallel Alliance. A student contacts several lecturers within the one virtual university. Each lecturer, contracted to be a member "organisation" within the VO, provides a part of the total course. The timing and content of each part must be coordinated by a regular exchange of Coordination information between the lecturers.

Example: A car body and the car doors may be designed and built by separate organisations. To ensure a final fit of door with body, design and design coordination information must be exchanged as work progresses.

\section{Summary and Conclusions}

A group of independent organisations that acts together for a common purpose is a "virtual organisation" or VO. This paper has presented a number of implications for management that flow from an understanding of the structure of the VO. By understanding the structure of the $\mathrm{VO}$ a manager may better plan for a suitable information and management structure.

The structures are from the i-based (information-based) taxonomy of virtual organisations. The taxonomy is based on necessary information flows between each organisation within the virtual organisation. The flows are planning, operational and coordination information. The structures in the VO taxonomy are: Virtual face, Star alliance, Market alliance, Coalliance, Value alliance and Parallel alliance.

A number of management implications apply to each of the VO structures. These will have different effects, depending on the structure of the virtual organisation.

- In some structures there is a core organisation. In a Market Alliance this is central to the VO role but with no VO management responsibility. In a Star Alliance the core organisation will manage the $\mathrm{VO}$ with planning and coordination information flows.
- VO members may be replaceable. A core organisation is difficult to replace, satellite organisations in a market alliance are readily added or removed, other member organisations in other structures need to be replaced by an organisation that can provide the same functions.

- Planning may be done by one or by all members. Many structures are planned in advance, once created they are difficult to change.

- Customer contact may be done by one member organisation, by several or by all.

- Management must suit each member, bearing in mind that each member may be replaced, and each member may also be operating in several other virtual organisations.

The i-based VO taxonomy provides a basis for understanding the structure of a VO. Understanding the structure leads to a better understanding of the requirements for effective management of that virtual organisation.

\section{References}

Ahuja, M. K., \& Carley, K. M. (1988). Network Structure in Virtual Organisations. Journal of Computer Mediated Communication, 3(4).

Angehrn, A. (1997). Designing Mature Internet Business Strategies: The ICDT Model. European Management Journal, 15(4), 361369.

Bultje, R., \& van Wijk, J. (1998). Taxonomy of Virtual Organizations, Based on Definitions, Characteristics and Typology. VOnet Newsletter, 2(3), 7-21.

Burn, J., \& Tetteh, E. O. (2000, June). A Strategic Approach to the Development of an Infrastructure for Small and Medium EBusiness. Paper presented at the Bled E-Commerce Conference, Bled.

Burn, J. M., \& Barnett, M. L. (1999). Communicating for Advantage in the Virtual Organisation. IEEE Transactions on Professional Communication, 42(4), 1-8.

Burn, J. M., Marshall, P., \& Wild, M. (1999). When Does Virtual Have Value? In C. T. Romm \& F. Sudaweeks (Eds.), Doing Business on the Internet: Opportunities and Pitfalls . London: Springer Verlag.

Bush, C. M., \& Robbins, S. S. (1991). What Does 'MIS' Really Mean? Journal of Systems Management, 42(6), 6-8.

Ginnodo, W. L. (1992). How TQM is redefining management and leadership. Tapping the Network Journal, 3(3), 8.

Hammer, M. (1990). Reengineering Work: Don't Automate, Obliterate. Harvard Business Review(July-August), 104-112.

Hoffman, D. L., Novak, T. P., \& Chaterjee, P. (1995). Commercial Scenarios for the Web: Opportunities and Challenges. Journal of Computer Mediated Communication, 1(3). 
Management Implications of an I-Based VO Taxonomy

Kanter, R. M. (1994). Collaborative Advantage: The Art of Alliances. Harvard Business Review, 72(July-August), 96-108.

Kibler, B. E. (1992). Integrated Cost and Schedule Control: A Piece of Cake. Cost Engineering, 34(7), 15-.

Klueber, R., Alt, R., \& Osterle, H. (1999). Emerging Electronic Services for Virtual Organizations - Concepts and Framework. Electronic Journal of Organizational Virtualness (eJOV), 190-212.

Lethbridge, N. (2000, 30 November and 1 December 2000). An I-Based (Information-Based) Taxonomy of Virtual Organisation Models. Paper presented at the Working for e-Business: Challenges of the New Economy, Perth, Australia.

Marshall, P., McKay, J., \& Burn, J. M. (2001). The Three S's of Virtual Organisations: Structure, Strategy and Success Factors. In Hunt \& Davnes (Eds.), E-Commerce and V-Business (pp. 171192): Butterworth Heinemann.
Sandhoff, G. (1999). Virtual Organizations as Power-asymmetrical Networks. Electronic Journal of Organizational Virtualness (eJOV), 103-117.

Sarkar, M. B., Butler, B., \& Steinfield, C. (1995). Intermediaries and Cybermediaries: A Continuing Role for Mediating Players in the Electronic Marketplace. Journal of Computer Mediated Communication, 1(3).

Sieber, P. (1998, 27-28 April, 1998). Organisational Virtualness: The Case of Small IT Companies. Paper presented at the WoNet Workshop, Bern, Switzerland.

Timmers, P. (1998). Business Models for Electronic Markets. EM Electronic Markets, 8(2), 3-8.

Yates, J. K., \& Rahbar, F. (1992). Setting Objectives for International Engineering and Construction. Project Management Journal, 23(2), 15-21. 